\title{
Expansão dos solos hidromórficos e mudanças na paisagem: um estudo de caso na região Sudeste da Amazônia Brasileira
}

\author{
Vania ROSOLEN ${ }^{1}$, Uwe HERPIN ${ }^{2}$ \\ RESUMO \\ Na região sudoeste da Amazônia brasileira, foi realizado um estudo detalhado da cobertura pedológica em uma toposseqüência \\ representativa da paisagem regional, caracterizada por baixos platôs com depressōes topográficas. Os resultados indicaram que \\ os processos pedogenéticos podem ser considerados como responsáveis pelo rebaixamento topográfico e mudanças da paisagem \\ natural. O principal fator envolvido neste processo de transformação é a expansão remontante da hidromorfia, a partir das \\ depressões topográficas desenvolvidas nas superfícies dos platôs. Este processo envolve transformações e degradações internas \\ na matriz do solo acarretando em modificações na estrutura, composição química e diminuição do volume do solo.
}

PALAVRAS-CHAVE: Depressão topográfica; Solo laterítico; Laterita hidromórfica; Rebaixamento topográfico.

\section{Expansion of hydromorphic soils and landscape changes: a case study in the Southwestern Brazilian Amazon}

\begin{abstract}
In the Southwestern Brazilian Amazon, a detailed study on the pedological cover of a representative toposequence for the region, characterized by lowered plateaus with topographic depressions, was carried out. The results indicated that pedogenic processes can be considered to be responsible for topographic smoothing and changes of the natural landscape. The main factor involved in this transformation process represents the upwards expansion of hydromorphic soil conditions from the topographic depressions developed in lower parts of the plateaus. This process includes internal transformations and degradations of the soil matrix leading to changes in soil structure, chemical composition and, diminishment of the original soil volume.
\end{abstract}

KEY-WORDS: Topographic depression; Lateritic soil; Groundwater laterite; topographic smoothing.

1 Universidade Federal de Uberlândia (UFU), IG, Av. João Naves de Ávila, 2121, Campus Santa Mônica, Uberlândia-MG, CEP: 38408-100. E-mail: vrosolen@ig.ufu.br. Telefone: (34) 32394169 .

2 Universidade de São Paulo (USP), NUPEGEL/ESALQ. Alameda das Sibipirunas, 44, Piracicaba-SP, CEP: 13418-900. E-mail: uwe.herpin@gmail.com. Telefone (19) 34294171. 


\section{INTRODUÇÃO}

O intemperismo é um dos mais cruciais e fundamentais fenômenos de desenvolvimento topográfico e de evolução das paisagens (McFarlane, 1974, Turkington, 2005). As mudanças físicas, químicas e biológicas que ocorrem in situ são fatores de degradação interna dos solos, da perda de volume e de mudanças nas paisagens naturais. Os processos de intemperismo atuam em diferentes escalas, desde o mineral até a evolução da paisagem. A atuação destes processos é necessária e precursora para todo tipo de denudação e fundamental para a evolução das formas do relevo e das paisagens da superfície (Viles, 2001, Phillips, 2005, Turkington et al., 2005).

Tradicionalmente, os modelos de evolução das paisagens consideraram o manto de intemperismo como o balanço entre da taxa de alteração e remoção. Quando pequenos desvios existem, como por exemplo irregularidades microtopográficas ou variaçōes litológicas, a atividade dos processos exógenos é maior e é conhecido como o princípio da instabilidade do equilíbrio geomórfico (Scheidegger, 1983). O aumento da instabilidade do sistema está ligado às mudanças do estoque ou fluxo de umidade, caracterizados pela condutividade hidráulica, permeabilidade e/ou porosidade (Nahon, 1991). O material gerado pelo intemperismo pode permanecer in situ ou ser removido por erosão, sob forma particulada ou dissolvida pelos fluxos de água superficial ou subsuperficial (Phillips, 2005). A relação entre a quantidade de material gerado e removido é a chave para a evolução da vertente.

A gênese e evolução dos solos estão diretamente relacionadas com o tipo de intemperismo e o avanço de processos geoquímicos pode refletir na modificação das formas de relevo e das paisagens superficiais. Alteração e pedogênese não são apenas desagregação e dissolução, elas intervêm como agentes de aplainamento superficial (Millot, 1977). Nas regiōes tropicais úmidas, a erosão geoquímica é responsável pelo aprofundamento contínuo das coberturas ferralíticas em equilíbrio (cobertura zonal em equilíbrio com o clima atual) o que provoca um rebaixamento lento da superfície topográfica (Boulet et al., 1977, Melfi et al., 1999).

A região sudoeste da Amazônia brasileira é uma extensa área onde ocorrem sedimentos paleógenos da Formação Solimões. A paisagem no contato floresta-savana é formada por platôs rebaixados, entre 150 e $200 \mathrm{~m}$ de altitude. Nas superfícies dos platôs desenvolvem-se depressōes conectadas ou não aos eixos de drenagem regional. Os mapeamentos do projeto Radambrasil (1978a, 1978b) individualizaram duas grandes unidades de solos: o Argissolo Vermelho-Amarelo e Plintossolo Háplico segundo a classificação Embrapa (2006).

No Brasil existem estudos que associam a formação e evolução de depressões topográficas com a exportação de material em solução (Suguio, 1969, Coltrinari, 1975,
Filizola e Boulet, 1996). A formação e o aprofundamento das depressões no tempo e no espaço foram explicados por modelos conceituais de organização e funcionamento das coberturas pedológicas (Nahon, 1991, Fritsch e Fitzpatrick, 1994, Peterschimitt et al., 1996). Foram diferenciados sistemas de transformação centrípeto, centrífugo ou, ainda, sistemas relacionados à expansão das zonas periódica ou constantemente saturadas por água, o que provocaria a mobilização, redistribuição e exportação do ferro, sílica, alumínio e outros elementos químicos.

O objetivo deste artigo é mostrar como a expansão da hidromorfia e a perda de matéria em uma depressão topográfica têm relaçôes com a evolução da vertente e da mudança futura da paisagem.

\section{MATERIAL E MÉTODOS}

\section{LOCALIZAÇÃO DA ÁREA}

A área de estudo situa-se na região sudoeste da bacia amazônica brasileira, entre as coordenadas de $8^{\circ} 18^{\prime} \mathrm{S}$ e $63^{\circ} 48^{\prime} \mathrm{O}$, próximo ao quilômetro 70 da rodovia BR-319 que liga as cidades de Porto Velho (RO) e Humaitá (AM) (Figura 1).

A cobertura vegetal presente na área de estudo é constituída pela floresta tropical úmida e pelos enclaves de campos de savana. Este mosaico vegetal é reflexo da alternância de episódios paleoambientais secos e úmidos que afetaram a região no Holoceno (Pessenda et al., 2001). Predominam os sedimentos da Formação Solimões (Plioceno superior/ Pleistoceno inferior) compostos predominantemente por arenitos quatzosos amarelo-avermelhados e secundariamente

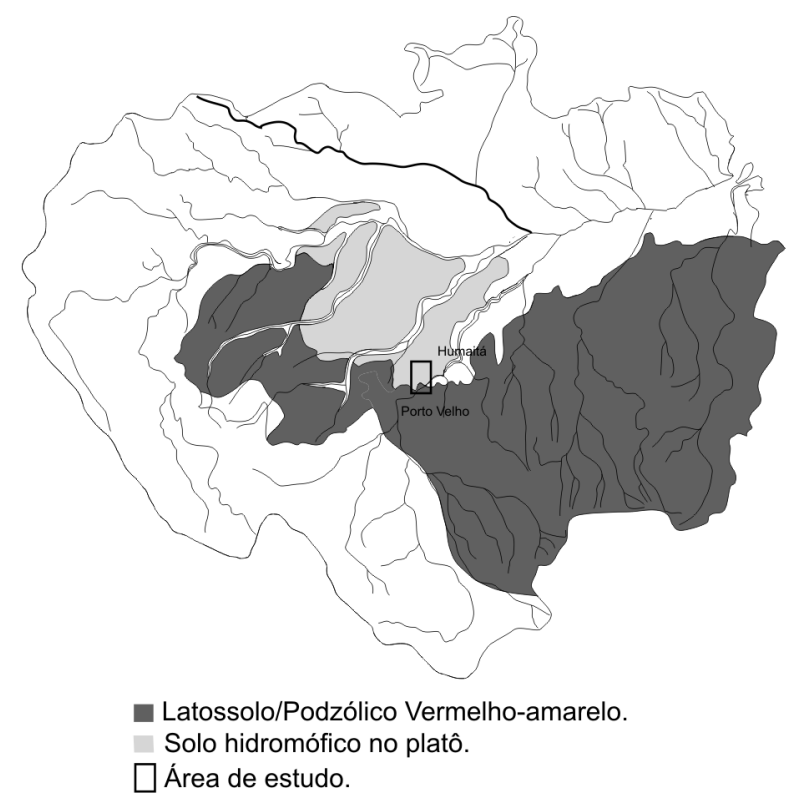

Figura 1 - Localização da área de estudo (Fonte: Projeto Dilat/Amazônia). 
arcoseanos, com siltitos e argilitos intercalados, finamente laminados a maciços, com espessura entre 200 e $800 \mathrm{~m}$, e os sedimentos fluviais holocênicos (Villas-Boas, 1993). A unidade morfoestrutural é o Planalto Rebaixado da Amazônia (Ocidental) (Radambrasil, 1978a). É uma extensa unidade de paisagem, com altitude entre 150 e $200 \mathrm{~m}$, aplainada, relevo pouco ou muito dissecado com interflúvios tabulares. Os platôs, separados pelos principais eixos de drenagem, apresentam numerosas depressões suaves, com desníveis métricos, que se desenvolvem desde a borda até o centro dos platôs. Essas depressões possuem diversas formas e tamanhos. Foram identificadas pelo Radambrasil (1978a) e denominadas de lagoas cuja dinâmica está relacionada com o regime pluviométrico, pois elas enchem e transbordam durante as chuvas e secam durante a estiagem. Ao transbordarem, algumas se interligam e formam uma rede de drenagem secundária. A precipitação média anual é de $2200 \mathrm{~mm}$ com curta época seca entre junho e agosto. A temperatura média anual é de $23^{\circ} \mathrm{C}$. Os solos são do tipo Podzólico Vermelho-amarelo e a Laterita Hidromórfica (Radambrasil, 1978a, 1978b) associados, respectivamente, as áreas de floresta e campo de savana. Porém, estudo detalhado realizado na toposseqüência indica a presença de Cambissolo Háplico na posição mapeada como Podzólico Vermelho-Amarelo e Gleissolo Húmico na posição mapeada como Laterita Hidromórfica pelo projeto Radambrasil (1978a).

\section{OBSERVAÇÕES DE CAMPO E MAPEAMENTO DA COBERTURA PEDOLÓGICA NA BACIA ELEMENTAR}

Antes do mapeamento dos solos na escala da bacia elementar foi feito estudo detalhado em uma vertente
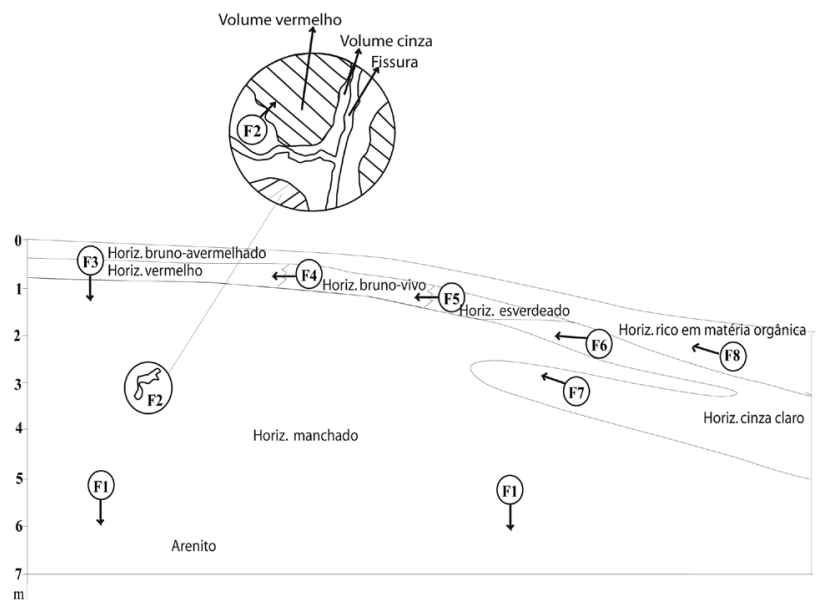

F1 Drenagem vertical. F2 horizonte manchado - processo de deferruginizacão. F3 Drenagem vertical. F4 Transformação do B vermelho em B bruno vivo. F5 Transformação do B bruno vivo em B esverdeado. F6 e F7 Expansão remontante do horizonte cinza claro.

Figura 2 - Frentes de transformação dos horizontes de solo na toposseqüência. representativa da paisagem regional. Esse estudo da cobertura do solo seguiu o conceito da análise estrutural proposto por Boulet et al. (1982a, 1982b). Esta proposta consiste em estudar detalhadamente a organização sucessiva dos horizontes e volumes de solo numa toposseqüência localizada entre o topo do interflúvio e o talvegue, seguindo a linha de maior declive. O reconhecimento da geometria dos volumes e horizontes em diferentes escalas de observação serviu de base para identificar a gênese e as transformaçôes dos solos na unidade de paisagem. Para este trabalho foi aberta uma trincheira de $90 \mathrm{~m}$ de extensão e $2,5 \mathrm{~m}$ de profundidade. A sua montante localiza-se na parte alta do platô sob cobertura de floresta e a jusante no centro da depressão sob cobertura de savana.

$\mathrm{Na}$ escala da bacia elementar o mapeamento foi realizado por tradagens em toposseqüências dispostas a partir do centro da depressão visando identificar as transições entre horizontes e matrizes (estruturas) do solo e definir espacialmente seus limites. Foram descritas 19 toposseqüências numa superfície de 10 ha e elaborada a carta de isolinhas de diferenciação dos horizontes de solo.

\section{ANÁLISES GRANULOMÉTRICA E QUIIMICA TOTAL}

Foram coletadas amostras de todos os horizontes para análise granulométrica seguindo o protocolo Embrapa (1997) que consiste na dispersão de uma alíquota de solo (10g) pela adição de $50 \mathrm{ml}$ de hexametafosfato e hidróxido de sódio. Após agitação mecânica (16h), a suspensão é peneirada (0,050mm) para separação da fração areia. A fração argila é extraída por pipetagem seguindo a Lei de Stockes e a fração silte calculada pela diferença entre as somas das frações areia e argila em relação à amostra total. $\mathrm{O}$ teor de $\mathrm{Fe}_{2} \mathrm{O}_{3}$ foi obtido por fluorescência de raios-X (Activation Laboratories LTD, Canadá) e o teor de Carbono Orgânico Total por espectrômetro de massa Optima (Universidade de Waterloo, Canadá).

\section{MEV E POROSIDADE}

O estudo ultramicroscópico da matriz do solo foi feito em lâminas delgadas de amostras indeformadas de solo recobertas por carbono. Usou-se um microscópio eletrônico de varredura Stereoscan Cambridge 90B equipado com um detector de elétrons retroespalhados (INRA-Orléans).

O tamanho dos poros da matriz foi determinado por porosimetria ao mercúrio usando um porosímetro Micromeritics Pore Sizer 9400 (NUPEGEL - USP) que mede poros entre 300 a $0,003 \mu \mathrm{m}$. Usaram-se torróes indeformados de aproximadamente $5 \mathrm{~mm}$ de diâmetro, secos em estufa a $110^{\circ} \mathrm{C}$ durante $24 \mathrm{~h}$ (Bruand e Prost, 1987). 


\section{RESULTADOS E DISCUSSÕES}

\section{OS SOLOS DA TOPOSSEQÜÊNCIA}

O perfil de montante apresenta seqüência vertical de horizontes, mais bem drenado e fortemente alterado que a jusante:

Horizonte bruno (Horizonte A moderado, $0-30 \mathrm{~cm}$ de profundidade): Bruno-acinzentado muito escuro (10YR $3,5 / 2$, seco) com numerosas manchas bruno vivo 7,5YR 4/6. Argiloso. Estrutura em blocos subangulares (1 a $4 \mathrm{~cm})$. Porosidade interagregados e tubular bastante desenvolvida.

Horizonte subsuperficial vermelho (Horizonte B Incipiente, 0-60 cm de profundidade): Fundo vermelho 2,5YR 5/6 com $20 \%$ de nódulos 10R 4/6 (2 a $3 \mathrm{~mm}$ ). Raros volumes irregulares vermelho $10 \mathrm{R} 5,5 / 8$ e preenchimentos biológicos amarelo-brunado 10YR 6/7. Argiloso. Estrutura em blocos angulares $(2 \mathrm{a} 3 \mathrm{~cm}$ ). Porosidade interagregados e tubular $(1 \mathrm{~mm})$ fraca.

Horizonte de transição (Horizonte de Transição B Incipiente - Horizonte Plíntico, $60-110 \mathrm{~cm}$ de profundidade): Associação de volumes vermelho 2,5YR 4/8 (até $80 \%$ do volume) e bruno-amarelado 10YR 6/4. Nódulos 10R 4/6 localizados no topo do horizonte. Argiloso. Estrutura blocos angulares. Porosidade tubular $(\mathrm{mm})$ irregularmente distribuída e cavidade $(5 \mathrm{~cm})$ com paredes revestidas de argila 10YR 4,5/2 (bruno-escuro) ou 2,5YR 4/8 (vermelho).

Horizonte de argila manchada (Horizonte Plíntico, 110$250 \mathrm{~cm}$ de profundidade): Comporta duas fases que se intercalam e possuem orientação preferencial vertical: (i) fase cinza-claro 10YR 7/2 com pequenos ( $\mathrm{mm}$ ) volumes vermelhos difusos. Estrutura em blocos angulares $(2-3 \mathrm{~cm})$ e prismática (quando o solo está seco). Porosidade interagregados e tubular fraca (inferior a $1 \mathrm{~mm}$ ). Coesão forte (seco). Presença de alguns tubos (5 a 10mm) de orientação vertical com paredes recobertas de argila cinza e com raízes $(\mathrm{mm})$ apodrecidas; (ii) fase vermelha e bruno-amarelada composta por $30 \%$ de volumes vermelho $10 \mathrm{R} 4 / 6$, alongados verticalmente (5 a $30 \mathrm{~mm}$ ), geralmente incluindo volumes mais escuros e mais endurecidos, e por $10 \%$ de volumes bruno-amarelado 10YR 5/6 situados nas bordas e/ou como filetes no interior dos volumes vermelhos. Estrutura blocos angulares $(2-3 \mathrm{~cm})$. Porosidade muito fraca.

\section{O SOLO DA DEPRESSÃO}

O perfil da jusante está submetido a condições de hidromorfismo temporário (aproximadamente 8 meses ao ano) e apresenta seqüência de horizontes superficiais ricos em matéria orgânica sobre um horizonte de coloração neutra. É o domínio hidromórfico em meio confinado com drenagem parcialmente impedida.
Horizonte preto (Horizonte A1 Húmico, 0-40 cm de profundidade): Argilo-orgânico, preto 10YR 2/1. Estrutura em blocos subangulares $(3 \mathrm{~cm})$ com subestrutura grumosa $(0,5 \mathrm{~cm})$. Porosidade tubular fina a média. Presença abundante de raízes $(\mathrm{mm})$ principalmente entre 0 e $20 \mathrm{~cm}$ de profundidade.

Horizonte cinza muito escuro (Horizonte A2 Húmico, 40-70 cm de profundidade): Cinza muito escuro 10YR 3/1. Argiloso. Estrutura em blocos angulares (2 a $3 \mathrm{~cm}$ ) pouco nítida. Porosidade tubular fina e grosseira $(\mathrm{mm})$ medianamente desenvolvida, com raras manchas bruno-amarelado-escuro 10YR 4/6 e fissuras verticais.

Horizonte acinzentado-escuro (Horizonte A3 Húmico, $70-120 \mathrm{~cm}$ de profundidade): Fundo bruno-acinzentado muito escuro 10YR 3,5/1 contém volumes $(\mathrm{mm})$ brunoamarelado 10YR 5/8 e vermelho 2,5YR 4/6. Argiloso. Presença de manchas esbranquiçadas. Estrutura prismática larga nítida (40 a $60 \mathrm{~cm}$ ), com argila lisa e brilhante nas faces dos prismas. Porosidade tubular grosseira (1 a $2 \mathrm{~mm}$ ) pouco desenvolvida.

Horizonte cinza-claro (Horizonte Glei, $120-250 \mathrm{~cm}$ de profundidade): Fundo cinza-claro $10 \mathrm{YR} 7 / 1$, comportando volumes milimétricos (10\%) vermelho 2,5YR 4/6 associados ou não a volumes difusos bruno-amarelado 10YR 6/6. Argiloso a argilo-siltoso. Maciço. Porosidade tubular fraca $(\mathrm{mm})$, com paredes freqüentemente bruno-amarelado 7,5YR 5/6.

\section{LATERAL ENTRE OS HORIZONTES DOS SOLOS DO PLATÔ E DA DEPRESSÃO}

Lateralmente, devido à topografia e hidromorfismo os horizontes superficiais da parte alta do platô e da meia encosta da vertente evoluem para os horizontes ricos em matéria orgânica da depressão (entre $0-5 \mathrm{~cm}$ de profundidade o teor de carbono orgânico aumenta de aproximadamente $3 \%$ para $10 \%$ e o teor de argila aumenta de 38,8 para $50,3 \%$ ) (Tabela 1).

Os horizontes subsuperficiais, dispostos acima de espesso horizonte manchado, evoluem lateralmente de vermelho para bruno vivo e, finalmente, para esverdeado. A evolução lateral reflete mudança de cor (diminuição da pigmentação vermelha com relíquias dos horizontes precedentes), sem variação de estrutura ou textura. A mudança da cor está associada à diminuição do teor de óxido de ferro que varia entre $10 \%$ de $\mathrm{Fe}_{2} \mathrm{O}_{3}$ no horizonte vermelho da montante, $4,3 \%$ no bruno vivo e $3 \%$ no esverdeado desenvolvido na borda da depressão (resultados detalhados do teor de ferro na toposseqüência foram apresentados em Rosolen et al., 2002). A formação desta seqüência de horizontes subsuperficiais, especificamente da formação do horizonte amarelo e esverdeado está relacionada ao início das condiçôes de hidromorfia devido à dissolução 
Tabela 1 - Composição química e mineralógica dos perfis do solo do platô (Cambissolo Háplico) e da depressão (Gleissolo Húmico).

\begin{tabular}{|c|c|c|c|c|c|c|}
\hline \multicolumn{7}{|l|}{$\begin{array}{l}\text { Perfil Cambissolo } \\
\text { Háplico }\end{array}$} \\
\hline Horizonte & $\begin{array}{l}\text { Prof. } \\
(\mathrm{cm})\end{array}$ & $\begin{array}{l}\text { Areia } \\
(\%)\end{array}$ & $\begin{array}{l}\text { Silte } \\
(\%)\end{array}$ & $\begin{array}{l}\text { Argila } \\
(\%)\end{array}$ & $\begin{array}{l}\mathrm{Fe} 203 \\
\mathrm{~g} / 100 \mathrm{~g}\end{array}$ & $\begin{array}{l}\text { C org. } \\
\mathrm{g} / 100 \mathrm{~g}\end{array}$ \\
\hline Bruno (A Moderado) & $0-5$ & 16,9 & 44,3 & 38,8 & 4,0 & 2,7 \\
\hline Bruno (A Moderado) & $10-15$ & 17,3 & 39,7 & 43,0 & n.d. & 1,9 \\
\hline Bruno (A Moderado) & $20-25$ & 17,3 & 38,7 & 43,9 & 5,0 & 1,2 \\
\hline $\begin{array}{l}\text { Subsuperficial } \\
\text { Vermelho (B } \\
\text { Incipiente) }\end{array}$ & $30-35$ & 15,5 & 39,1 & 45,4 & n.d. & 0,8 \\
\hline $\begin{array}{l}\text { Subsuperficial } \\
\text { Vermelho (B } \\
\text { Incipiente) }\end{array}$ & $40-45$ & 15,1 & 38,7 & 46,2 & 10,0 & 0,6 \\
\hline $\begin{array}{l}\text { Transição (transição B } \\
\text { Incipiente-Plíntico) }\end{array}$ & $90-100$ & 11,8 & 31,1 & 57,1 & 10,6 & 0,2 \\
\hline $\begin{array}{l}\text { Argila Manchada } \\
\text { (Plíntico) }\end{array}$ & $120-130$ & 14,9 & 28,7 & 56,4 & 9,3 & 0,2 \\
\hline $\begin{array}{l}\text { Argila Manchada } \\
\text { (Plíntico) }\end{array}$ & $150-160$ & 15,1 & 30,7 & 54,2 & 8,2 & 0,1 \\
\hline $\begin{array}{l}\text { Argila Manchada } \\
\text { (Plíntico) }\end{array}$ & $200-210$ & 31,2 & 25,6 & 43,2 & n.d. & n.d. \\
\hline $\begin{array}{l}\text { Argila Manchada } \\
\text { (Plíntico) }\end{array}$ & $270-280$ & 29,5 & 27,5 & 43,0 & 5,9 & n.d. \\
\hline \multicolumn{7}{|l|}{$\begin{array}{l}\text { Perfil Gleissolo } \\
\text { Húmico }\end{array}$} \\
\hline Preto (A1 Húmico) & $0-5$ & 7,4 & 42,3 & 50,3 & 1,7 & 9,9 \\
\hline Preto (A1 Húmico) & $10-15$ & 2,4 & 34,7 & 62,9 & 1,7 & 6,5 \\
\hline Preto (A1 Húmico) & $20-25$ & 1,9 & 33,2 & 64,9 & 2,5 & 5,1 \\
\hline Preto (A1 Húmico) & $30-35$ & 1,5 & 29,6 & 68,9 & n.d. & 2,9 \\
\hline $\begin{array}{l}\text { Cinza muito escuro } \\
\text { (A2 Húmico) }\end{array}$ & $50-55$ & 1,8 & 27,9 & 70,3 & 3,3 & 1,7 \\
\hline $\begin{array}{l}\text { Acinzentado-escuro } \\
\text { (A3 Húmico) }\end{array}$ & $80-85$ & 5,6 & 28,3 & 66,1 & 3,8 & 0,7 \\
\hline Cinza claro (Glei) & $110-120$ & 13,2 & 42,7 & 44,1 & n.d & 0,4 \\
\hline Cinza claro (Glei) & $140-150$ & 22,6 & 50,9 & 26,5 & 1,0 & 0,1 \\
\hline Cinza claro (Glei) & $170-180$ & 26,7 & 50,3 & 23,1 & 1,7 & n.d. \\
\hline
\end{tabular}

n.d. = não determinado ou abaixo do limite de detecção instrumental.

seletiva dos óxi-hidróxidos de ferro (Peterschmitt et al., 1996).

Os horizontes manchados (plíntico) têm a gênese ligada à flutuação sazonal do lençol. Na estação seca, o teto do lençol varia de 4,8 a $5,5 \mathrm{~m}$ de profundidade a montante no platô e de 5,5 a $5,8 \mathrm{~m}$ de profundidade a jusante na depressão. Com o início da estação chuvosa a subida do lençol é rápida. O teto do lençol se eleva para $2 \mathrm{~m}$ de profundidade na montante e alcança a superfície do solo na depressão. Com o avanço da estação chuvosa, o lençol atinge entre 1 e $1,5 \mathrm{~m}$ na montante e o nível da água na depressão sobe para $0,5 \mathrm{~m}$ acima do nível da superfície. O esvaziamento da depressão ocorre por escoamento subsuperficial ou pelo transbordamento para o igarapé.

A montante, a seqüência de horizontes sobrepostos e diferenciados reflete evolução vertical: os horizontes com predomínio de manchas vermelhas evoluem para o vermelho em subsuperfície. É litodependente, pois se inicia com a alteração do sedimento areno-siltoso amarelo-avermelhado da Formação Solimões em condições de flutuação de lençol. O resultado é a formação do horizonte manchado composto basicamente por quartzo residual, caulinita, pouca ilita e óxidos de ferro (hematita e goethita). O horizonte subsuperficial vermelho possui matriz homogênea e reflete boas condições de drenagem que provoca a redistribuição de argila (caulinita e traços de vermiculita aluminosa) e difusão dos óxidos de ferro. Esta filiação genética entre horizontes desde a rocha alterada até o horizonte superficial é definida por Nahon (1991) como unidade estrutural original.

Existe relação genética entre os horizontes manchados do platô e da meia encosta da vertente com o horizonte branco da depressão (Rosolen et al., 2002). Em direção a jusante, progressivamente, os volumes cinza do horizonte manchado tornam-se cada vez mais abundantes, mais claros e maiores. A interrupção da argila manchada ocorre na forma língua próximo ao centro da depressão. Do centro da depressão em direção a montante, os horizontes brancos expandem-se discordantes em relação à superfície, na forma de cunha, o que provoca a transformação e desaparecimento dos horizontes da montante. Esta seqüência discordante da unidade original é denominada por Nahon (1991) de unidade estrutural derivada. O horizonte branco apresenta forte eluviação de argila em relação ao horizonte manchado (teor de $23 \%$ de argila no horizonte branco a $195 \mathrm{~cm}$ de profundidade e $54 \%$ no horizonte manchado a $155 \mathrm{~cm}$ de profundidade).

Seqüências com horizontes similares foram estudadas em outros países como na Guiana, Austrália, Índia e são consideradas pelos autores como a evolução pedogenética típica das regiōes tropicais (Daniels et al., 1975, Williams e Coventry, 1979, Fritsch e Fitzpatrick, 1994, Peterschmitt et al., 1996, Melfi et al., 1999).

\section{DOS PRINCIPAIS HORIZONTES NA BACIA ELEMENTAR}

Há uma estreita relação entre a distribuição dos principais horizontes dos solos, a topografia e a variação da vegetação (Figuras 3a e 3b). A presença dos horizontes ricos em matéria orgânica e dos horizontes cinza-claro é sistemática e exclusivamente associada às áreas deprimidas. A partir dessas zonas deprimidas, a distribuição dos horizontes relacionados com as posiçôes elevadas da vertente é radial. Não há relação entre a distribuição da vegetação com a organização dos horizontes. A floresta recobre tanto as áreas deprimidas, com horizontes orgânicos acima de horizontes cinza claro, quanto às 

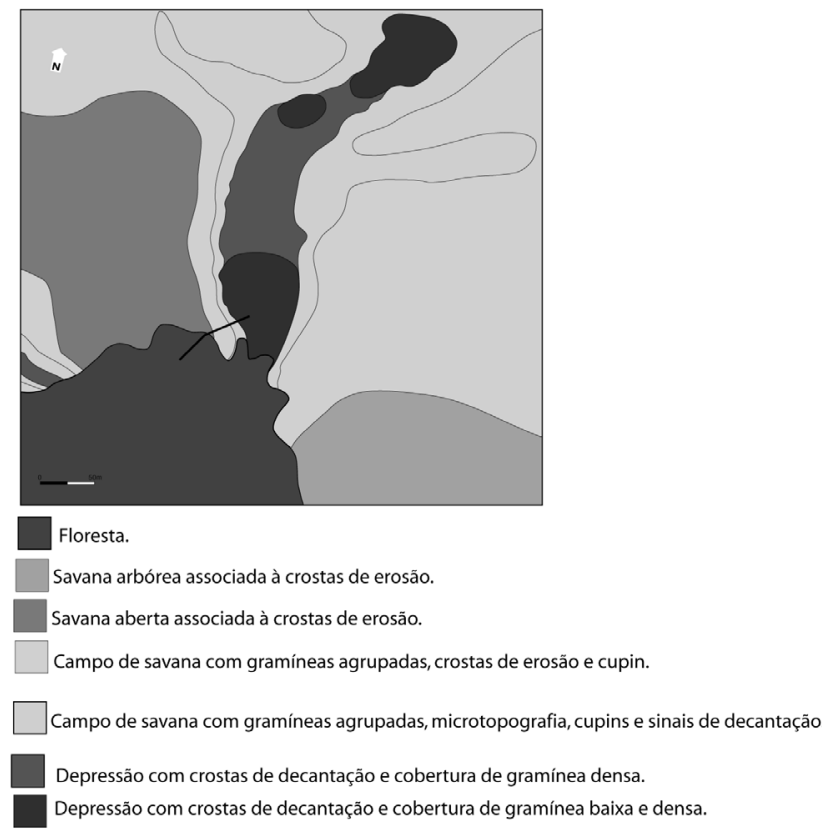

Figura 3 - (a) Feições da superfície do solo e relação com a vegetação e (b) (Dilat/Amazônia).

áreas elevadas, com horizontes predominantemente vermelho (B Incipiente) sobre horizonte manchado (Plíntico). O mesmo ocorre sob a vegetação de savana. O limite floresta-savana (figura 3a) é discordante da topografia e com as características do solo (figura $3 b$ ). Deste ponto de vista, a toposseqüência estudada reflete predominantemente as diferenciaçôes determinadas pela topografia e não pela vegetação.

\section{HIPÓTESE SOBRE A AMPLIAÇÃO DA DEPRESSÃO E EVOLUÇÃO DA PAISAGEM}

As transformações dos horizontes de solo na toposseqüência refletem a dinâmica evolutiva espacial e temporal do sistema na escala da bacia elementar. As mais nítidas frentes de transformação lateral são provocadas pela expansão, em cunha, dos horizontes hidromórficos que avançam para montante a partir do centro da depressão transformando os horizontes manchados (Plíntico) e a base do horizonte subsuperficial esverdeado (horizonte Incipiente bruno oliva claro, 10 YR 5/3 seco). O horizonte cinza claro (Horizonte Glei) é eluvial, com perda acentuada de argila seja na forma particulada ou por hidrólise. A perda por hidrólise parece ser mais efetiva, pois

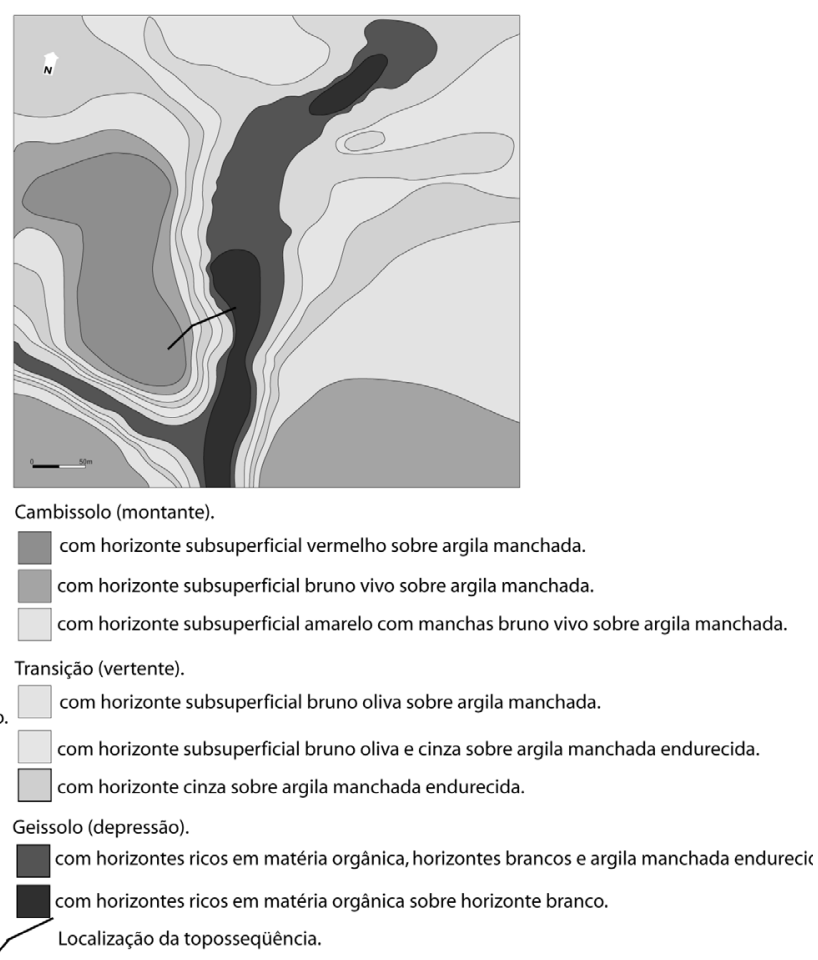

(b) Distribuição dos horizontes dos solos em uma área representativa de 10ha

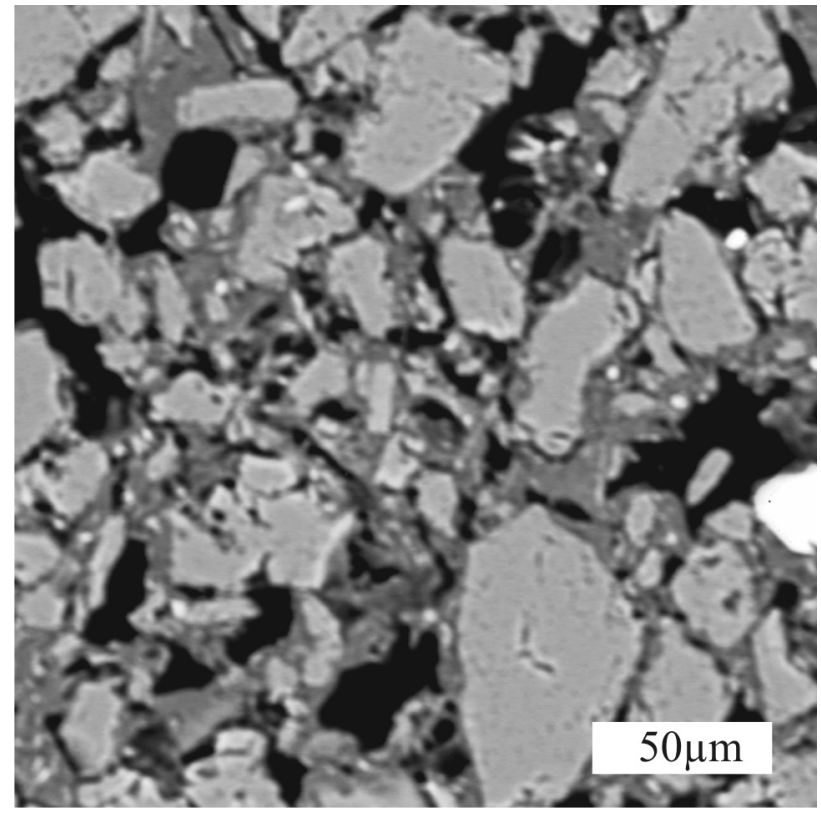

Figura 4 - Perda de argila (zonas pretas) no horizonte cinza claro desenvolvido na depressão. 
há também a perda de elementos como $\mathrm{Fe}_{2} \mathrm{O}_{3}, \mathrm{~K}_{2} 0, \mathrm{MgO}$ e $\mathrm{Al}_{2} \mathrm{O}_{3}$ (Rosolen et al., 2002).

Globalmente, a evolução geoquímica indica empobrecimento da cobertura pedológica ocorre por perda do plasma ferruginoso e afeta os horizontes superficial e subsuperficial esverdeado da meia encosta (até $1 \mathrm{~m}$ de profundidade) e, de forma muito mais marcante, o horizonte cinza da jusante onde foi determinada perda seletiva de constituintes (óxi-hidróxidos de ferro e caulinita). A diminuição do teor de argila é pequena na média vertente e grande na depressão e indica perda lateral no centro da depressão. Este processo se expande para o meio da vertente coincidindo com os limites do horizonte branco. Como resultado há homogeneização do tamanho das partículas na matriz do solo com predomínio do esqueleto quartzoso e surgimento de nova porosidade, de forma irregular e diâmetro maior (tipo "cárie") entre 0,2 e 30 $\mu \mathrm{m}$ com diâmetro modal a $2,5 \mu \mathrm{m}$ (Figura 4).

No horizonte manchado (Plíntico) com alto teor de argila, os poros variam entre 0,003 e $30 \mu \mathrm{m}$ com diâmetro modal a $0,04 \mu \mathrm{m}$. A geometria do espaço poroso reflete organização estrutural e textural da matriz. As transformações mais importantes estão refletidas na passagem do horizonte manchado para o horizonte cinza com diminuição global da microporosidade e aumento da porosidade ligada a eluviação do plasma argiloso da matriz. A estrutura muda de poliédrica para maciça. A separação entre o plasma ferruginoso e o esqueleto quatzoso é o motor de severas transformaçôes internas (Millot, 1977). Em estaçōes contrastadas, o plasma migra lateralmente, o esqueleto se reorganiza e há perda volume. Há a formação e o aprofundamento da depressão por subtração de matéria. $\mathrm{O}$ aumento da porosidade acentua a permeabilidade e o grau de intemperismo. $\mathrm{O}$ avanço deste processo denominado de intemperismo centrífugo (Fritsch $e t$ al., 1986) ou divergente (Phillips, 2005) causa o progressivo alargamento e amplificação das pequenas variações iniciais, expondo as transformaçōes na topografia (Gunnell e Louchet, 2000, Phillips, 2005). No caso em estudo, a abertura do sistema e a ampliação do "ponto de fuga" é a conexão da depressão com o eixo de drenagem. A perda de matéria aprofunda a depressão sobre o platô e resulta em diminuição do desnivelamento topográfico, aplainamento do relevo e aumento da extensão da área a ser alagada sazonalmente. $\mathrm{O}$ alargamento ocorre pela progressão lateral remontante, a partir do ponto de fuga. A progressão lateral do horizonte gerado (horizonte esbranquiçado) é feita em detrimento da organização do solo original (seqüência vertical na montante no platô). Sua extensão espacial é lateral centrífuga em relação ao eixo da depressão (jusante da vertente) com uma dinâmica lateral remontante no modelado.

\section{CONCLUSÃO}

Nos sedimentos areno-siltosos da Formação Solimões na região sudoeste da Amazônia brasileira, a expansão das coberturas hidromórficas se dá a partir das depressões topográficas em uma dinâmica evolutiva essencialmente lateral. Ela se traduz na exportação de matéria fina que modifica a textura, a estrutura e as propriedades geoquímicas da matriz. A perda de matéria particulada e/ou dissolvida resulta em perda de volume que tenderá progressivamente ao aplainamento da vertente e rebaixamento do interflúvio na paisagem. Considerando que a área de estudo é representativa de uma grande região da Amazônia, e que, existe uma regularidade na distribuição das depressões nas superfícies dos planaltos, acredita-se que o processo de alargamento das depressóes é generalizado. $\mathrm{O}$ estudo realizado permite predizer que a dinâmica apresentada é típica da paisagem regional. A evolução das formas de relevo tende a aumentar a extensão das áreas com solos que exibem padróes e propriedades associados à estagnação de água, com lençol freático temporário superficial. Finalmente, é importante salientar que, embora este processo de evolução da paisagem seja um processo natural, ele pode ser intensificado pelo uso antrópico através do aumento da velocidade de transformação e possível degradação dos solos.

\section{AGRADECIMENTOS}

Gostaríamos de agradecer à FAPESP (Processos 96/1447 e 97/01550-0) pelo suporte financeiro ao projeto de pesquisa e ao NUPEGEL/USP pela infra-estrutura.

\section{REFERÊNCIAS}

Boulet, R.; Bocquier, G.; Millot, G. 1977. Géochimie de la surface et formes du relief. I. Déséquilibre pédobioclimatique dans les covertures pédologiques de l'Áfrique tropicale de l'Ouest et son rôle dans le aplanissement des reliefs. Science Géologique Buletin, 30: 235-243.

Boulet, R.; Chauvel, A. ; Humbel, F.X. ; Lucas, Y. 1982a. Analyse structurale et cartographie en pédologie: I. Prise en compte de l'organisation bidimensionnelle de la coverture pédologique: les études de toposséquences et leurs principaux apports à la connaissance des sols. Cahier ORSTOM, série Pedologie, XIX (4): 309-321.

Boulet, R.; Humbel, F.X. ; Lucas, Y. 1982b. Analyse structurale et cartographie en pédologie: II. Une méthode d'analyse prenant en compte l'organisation tridimensionnelle des couvertures pédologiques. Cahier ORSTOM, série Pedologie, XIX (4): $323-$ 339.

Bruand, A.; Prost, R. 1987. Effect of water content on the fabric of a soil material: an experimental approach. Journal of Soil Science, 38: 461-472. 
Coltrinari, L. 1975. Contribuição a geomorfologia da regiāo de Guaratinguetá-Aparecida. Série teses e monografias, Instituto de Geografia - USP, São Paulo, SP., 17: 156p.

Daniels, R.B.; Gamble, E.E.; Buol, S.W.; Bailey, H.H. 1975. Free iron sources in an Aquult-Udult sequence from North Carolina. Soil Science Society American Journal, 39: 335-340.

EMBRAPA. Empresa Brasileira de Pesquisa Agropecuária. 1997. Manual de métodos de análise de solos. Rio de Janeiro. 212p.

EMBRAPA. Empresa Brasileira de Pesquisa Agropecuária. 2006. Sistema Brasileiro de Classificação de solos. $2^{a}$ edição. Rio de Janeiro. 306p.

Filizola, H.F.; Boulet, R. 1996. Evolution and opening of closed depressions developed in a quartz-kaolinitic sedimentary substratum at Taubaté basin (São Paulo, Brazil), and analogy to the slope evolution. Geomorphology, 16: 77-86.

Fritsch, E. 1986. Les transformations d'une paysage cuirassé au Nord-Ouest de la Cote-d'Ivoire sur formation gneissomigmatitique. Séminaire Régional Sur les Latérites. Colloques et Séminares. ORSTOM, Douala, 59-76p.

Fritsch, E.; Fitzpatrick, R.W. 1994. Interpretation of soil features produced by ancient and modern processes in degraded landscapes: I. a new method for constructing conceptual soilwater-landscape models. Australian Journal of Soil Research, 32: 889-907.

Gunnell, Y.; Louchet, A. 2000. The influence of rock hardness and divergent weathering on the interpretation of apatite fission track denudation rates. Z. Geomorphology, 44: 33-57.

McFarlane, M.J. 1974. Laterization and landscape development in Kyagwe, Uganda. Q.J. Geological Society of London, 126: 501-539.

Melfi, A.J.; Cerri, C.C.; Fritsch, E.; Formoso, M.L.L. 1999. Tropical soils: genesis, distribution and degradation of lateritic pedological systems. In : Formoso, M.L.L.; Cerri, C.C. (Org.). Workshop on Tropical Soils, Academia Brasileira de Ciências, Rio de Janeiro. 7-30pp.

Millot, G. 1977. Geochemie de la surface et formes du relief: présentation. Science Géologique Bulletin, 30(4): 229-233.

Nahon, D.B. 1991. Introduction to the petrology of soils and chemical weathering. Wiley-Interscience, New York. 313p.
Pessenda, L.C.R.; Boulet, R.; Aravena, R.; Rosolen, V.; Gouveia, S.E.M.; Ribeiro, A.S.; Lamotte, M. 2001. Origin and dynamics of soil organic matter and vegetation changes during the Holocene in a forest-savanna transitionzone, Southern Amazonas State, Brazilian Amazon Region. The Holocene, 11(2): 250254.

Peterschmitt, E.; Fritsch, E.; Rajot, J.L.; Herbillon, A.J. 1996. Yellowing, bleaching and ferritisation processes in soil mantle of the Western Ghâts, South India. Geoderma, 74: 235-253.

Phillips, J. D. 2005. Weathering instability and landscape evolution. Geomorphology, 67: 255-272.

RADAMBRASIL. 1978a. Porto Velho-SC-20. Levantamento de recursos naturais. Vol. 16. Ministério das Minas e Energia. Departamento de Produção Mineral, Rio de Janeiro. 663p.

RADAMBRASIL. 1978b. Purus-SB-20. Levantamento de recursos naturais. Vol. 17. Ministério das Minas e Energia. Departamento de Produção Mineral, Rio de Janeiro. 561p.

Rosolen, V.; Lamotte, M.; Boulet, R.; Trichet, J.; Rouer, O.; Melfi, A.J. 2002. Genesis of a mottled horizon by Fe-depletion within a laterite cover in the Amazon Basin. Comptes Rendus de l'Académie de Sciences, Série Geoscience, 334: 187-195.

Scheidegger, A.E. 1983. The instability principle in geomorphic equilibrium. Z. Geomorphology, 27: 1-19.

Suguio, K. 1969. Contribuição à geologia da Bacia de Taubaté, Vale do Paraíba, Estado de São Paulo. Boletim Especial da Faculdade de Filosofia, Ciências e Letras - USP, 130p.

Turkington, A.V.; Phillips, J.D.; Campbell, S.W. 2005. Weathering and landscape evolution. Geomorphology, 67: 1-6.

Williams, J; Coventry, R. J. 1979. The contrasting hydrology of red and yellow earths in a landscape of low relief. In: The hydrology of Areas of Low Precipitation. Proceeding Canberra Symposium - International Association of Hydrological Science, 128: 385-395.

Villas-Boas, P.F. 1993. Projeto Alto Rio Negro. Relatório preliminar. MME/CPRM.

Viles, H.A. 2001. Scales issues in weathering studies. Geomorphology, 41: 63-71.

Recebido em 25/05/2007

Aceito em 23/03/2008 